\title{
Estresse hídrico e época de produção da lima ácida 'Tahiti'1
}

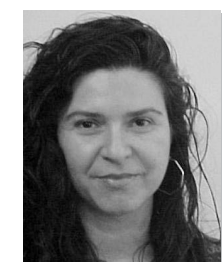

Maria J. H. de Souza², Márcio M. Ramos ${ }^{3}$, Dalmo L. de Siqueira ${ }^{4}$, Luiz C. Costa ${ }^{5}$, Arnaldo J. M. Lhamas ${ }^{6}$, Everardo C. Mantovani ${ }^{7}$, Paulo R. Cecon ${ }^{8} \&$ Luiz C. C. Salomão ${ }^{4}$

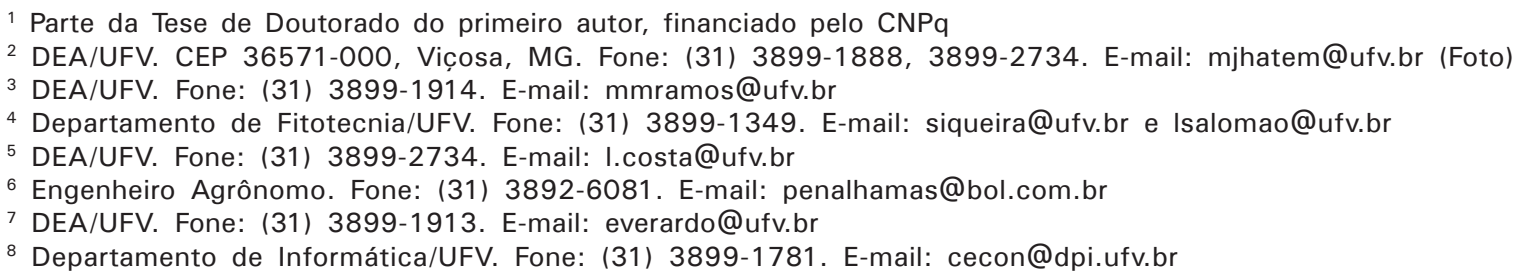

Protocolo 164 - 6/11/2002 - Aprovado em 25/1/2004

\begin{abstract}
Resumo: Avaliou-se, neste trabalho, a influência do período do estresse hídrico sobre a distribuição temporal da produção da lima ácida 'Tahiti', no período de novembro de 2000 a novembro de 2001. O experimento foi conduzido em Visconde do Rio Branco, MG. Os tratamentos consistiram de quatro períodos de estresse hídrico, isto é: sem estresse (SE), estresse curto (EC), estresse médio (EM) e estresse longo (EL) proporcionados por quatro períodos sem irrigação (0, 7, 10 e 13 semanas) durante os meses de junho a agosto de 2000 e de maio a julho de 2001, e de três porcentagens de área molhada, assim como da testemunha (tratamento não-irrigado) totalizando $13(12+1)$ tratamentos. O estresse hídrico reduziu a produção de frutos das árvores, durante o período de sua aplicação, e aumentou a produção nos meses subseqüentes ao estresse. A duração do estresse influenciou a produtividade sazonal da lima ácida, deslocando a época das maiores produções nos tratamentos de estresse, porém não influenciou significativamente a produção total. Para novembro e dezembro de 2000, o tratamento EM proporcionou a maior produção, o mesmo ocorrendo com o tratamento, para os meses de outubro e novembro de 2001.
\end{abstract}

Palavras-chave: Citrus latifolia Tanaka, manejo da água, produtividade sazonal, déficit hídrico

\section{The water stress and the production time in 'Tahiti' lime}

\begin{abstract}
This study was carried out in the muncipality of Visconde do Rio Branco, MG, and had as objective to evaluate the influence of the water management on temporary yield distribution of the 'Tahiti' lime, during the period from November, 2000 to November, 2001. The treatments consisted of four periods with water stress: no stress (SE), short stress (EC), medium stress (EM), and long stress (EL). These treatments corresponded to four periods without irrigation: 0 , 7, 10 and 13 weeks, during the months from June to August, 2000, and from May to July, 2001, and three percentages of the wetted area, as well as the control (nonirrigated treatment), totalizing $13(12+1)$ treatments. Soil water stress reduced the fruit yield of the trees during the period of the water stress application, and increased it during the months subsequent to water stress. The duration of the water stress affected the yield and the seasonal productivity of the acid lime, but had no significant influence upon total yield. For November and December, 2000 the EM treatment provided the highest yield, whereas for October and November, 2001 the EC treatment provided the highest yield.
\end{abstract}

Key words: Citrus latifolia Tanaka, water management, seasonal productivity, water deficit

\section{INTRODUÇÃO}

A lima ácida 'Tahiti' (Citrus latifolia Tanaka), conhecida como limão 'Tahiti', destaca-se, no Brasil, como uma das frutas cítricas de maior importância comercial.
Os preços da lima ácida 'Tahiti' nem sempre são compensadores, em virtude da oferta concentrada no período de safra; entretanto, o preço pode ser cinco a dez vezes maior no período de entressafra. Segundo os dados fornecidos pelo CEAGESPSP, apresentados no AGRIANUAL (1999) o preço médio mensal 
da lima ácida 'Tahiti', no período de 1992 a 1998, no Estado de São Paulo, variou de US\$ $180 \mathrm{t}^{-1}$, em maio, a US\$ $1.210 \mathrm{t}^{-1} \mathrm{em}$ outubro. Tal fato incentiva a procura de alternativas que possibilitem alterar a época de floração no sentido de favorecer a produção na entressafra. Dentre as alternativas viáveis destacam-se o uso de reguladores de crescimento (Caetano et al., 1981; Southwick \& Davenport, 1987; Marcondes \& Coelho,1996); o uso de outros porta-enxertos, além do limão 'Cravo' (PESAGRO-RIO, 1999), e o uso da irrigação e de técnicas de manejo da água (Vieira, 1988a, 1988b; Coelho,1993).

Nos citros um período de repouso é essencial para floração, pois a duração deste período determina a quantidade de flores produzidas. O período de repouso, preferivelmente com dois meses de duração, pode ser induzido tanto por meio de temperaturas baixas de inverno (em torno de $10^{\circ} \mathrm{C}$ ) nas zonas subtropicais, quanto por um período de déficit hídrico nas zonas tropicais (Doorenbos \& Kassam, 1979). O período de repouso resulta em um acúmulo de reservas pela planta, as quais são rapidamente consumidas na florada, durante o desenvolvimento das estruturas reprodutivas (Lima, 1989).

Southwick \& Davenport (1986) estudaram os efeitos do estresse hídrico e das baixas temperaturas sobre a indução floral da lima ácida 'Tahiti'. Neste trabalho, avaliou-se o número de flores obtidas em plantas com um a dois anos de idade cultivadas em vasos, em casa de vegetação, submetidas a vários tratamentos de estresse hídrico, sendo eles: controle, estresse hídrico contínuo moderado de 2, 3, 4 e 5 semanas (mantendose, por meio de irrigação controlada, o potencial hídrico xilemático da planta ao meio dia, de $-2,5 \mathrm{MPa}$ ), estresse hídrico contínuo severo durante $2,3,4$ e 5 semanas $(-3,5 \mathrm{MPa})$ e o estresse hídrico cíclico (reiniciavam-se as irrigações quando o potencial de água no solo atingia o ponto de murcha). Os resultados obtidos mostraram que tanto o estresse hídrico cíclico quanto o contínuo de 4 a 5 semanas induziram uma floração maior na lima ácida. As baixas temperaturas $\left(10^{\circ} \mathrm{C}\right.$ à noite e $18^{\circ} \mathrm{C}$ durante o dia) também aumentaram o número de flores, provocando uma resposta de florescimento mais significativa que aquela produzida por estresse hídrico moderado.

Sanches et al. (1989), avaliando os efeitos da irrigação sobre a formação de flores e queda de frutos jovens no limoeiro 'Verna' (Citrus limonum L.) verificaram uma floração mais precoce e mais intensa quando as plantas foram submetidas a déficit hídrico.

Segundo Hall et al. (1977) temperaturas diurnas de $20{ }^{\circ} \mathrm{C}$ e noturnas de $15^{\circ} \mathrm{C}$ proporcionaram maior número de flores na cultivar de laranja 'Valência' (Citrus sinensis L. Osbeck) quando comparadas às temperaturas de $30^{\circ} \mathrm{C}$ de dia e $15^{\circ} \mathrm{C}$ à noite. $\mathrm{Os}$ autores avaliaram, também, o efeito da temperatura do solo sobre o florescimento mostrando que, ao contrário da temperatura do ar, temperaturas mais elevadas no solo $\left(25^{\circ} \mathrm{C}\right)$ induziram a um número maior de flores que as mais baixas $\left(15^{\circ} \mathrm{C}\right)$.

As sucessivas brotações da lima ácida dão origem a várias floradas que, por sua vez, podem resultar em diversas colheitas ao longo do ano, mas as flores e frutos se perdem em virtude da seca e dos veranicos. A aplicação sistemática de um programa de irrigação evita esta ocorrência, possibilitando a obtenção de uma boa produção fora da safra (Vieira, 1988a). No vale do Rio São Francisco, o manejo da irrigação durante o cultivo da lima ácida 'Tahiti', associado a adubações mais pesadas e pulverizações com micronutrientes, efetuadas no primeiro semestre, tem permitido maiores produções na entressafra (Coelho, 1993).

No Brasil, para obtenção de uma produção satisfatória de lima ácida na entressafra é necessário que estudos sejam conduzidos no sentido de avaliar a influência do manejo da água sobre a época de produção. Por tal motivo, este trabalho teve como objetivo estudar o manejo da água, em árvores de lima ácida 'Tahiti' irrigadas por microaspersão, para determinar qual a duração do período de estresse a que as plantas devem ser submetidas para proporcionar um déficit hídrico que induza a uma floração mais precoce e maiores produção na entressafra, para a região de Visconde do Rio Branco, MG.

\section{MATERIAL E MÉTODOS}

O estudo foi conduzido em árvores de lima ácida 'Tahiti' (Citrus latifolia Tanaka) enxertadas no limão 'Cravo' (Citrus limonia Osbeck) e plantadas em dezembro de 1996. O pomar está localizado na Estação Experimental da Sementeira, pertencente à Universidade Federal de Viçosa e localizada em Visconde do Rio Branco, MG (21 ${ }^{\circ} 07^{\prime} \mathrm{S}, 42^{\circ} 27^{\prime} \mathrm{W}, 349 \mathrm{~m}$ de altitude).

A encosta onde foram plantadas as árvores de lima ácida 'Tahiti', encontra-se voltada para Oeste, cuja área de 0,77 ha foi cultivada com 205 árvores, com espaçamento $6 \times 7 \mathrm{~m}$, irrigadas por microaspersão.

O solo do local foi classificado como Latossolo VermelhoAmarelo Distrófico. As características físicas desse solo podem ser visualizadas na Tabela 1 . As curvas de retenção de água no solo (Figura 1), foram ajustadas aos potenciais matriciais correspondentes a $-0,01 ;-0,03 ;-0,1 ;-0,3 ;-1,0$ e $-1,5 \mathrm{MPa}$, pelo modelo proposto por van Genuchten (1980), sendo a estimativa dos parâmetros $\theta_{\mathrm{s}}$ e $\theta_{\mathrm{r}}$ feita pelo método proposto por van Lier \& Dourado Neto (1993):

$$
\theta=\theta_{\mathrm{r}}+\frac{\left(\theta_{\mathrm{s}}-\theta_{\mathrm{r}}\right)}{\left[1+\left(\alpha\left|\Psi_{\mathrm{m}}\right|\right)^{\mathrm{n}}\right]^{\mathrm{m}}}
$$

em que $\theta$ é a umidade à base de volume, $\mathrm{kg} \mathrm{kg}^{-1} ; \theta_{\mathrm{s}}$ é a umidade de saturação estimada, $\mathrm{kg} \mathrm{kg}^{-1} ; \theta_{\mathrm{r}}$ é a umidade residual estimada, $\mathrm{kg} \mathrm{kg}^{-1} ; \Psi_{\mathrm{m}}$ é o módulo do potencial matricial expresso em $\mathrm{cm}$ de coluna de água; $\alpha$ é o parâmetro empírico, expresso em $\mathrm{cm}^{-1} ; \mathrm{n}$ e m são parâmetros empíricos adimensionais, com a restrição $m=1-1 / n$. Estes parâmetros estão na Tabela 1 .

$\mathrm{O}$ experimento foi conduzido em parcelas subdivididas, tendo nas parcelas três porcentagens de área molhada e, nas subparcelas, os períodos de estresse, em um delineamento em blocos casualizados, com três repetições.

Os tratamentos consistiram de quatro períodos de estresse hídrico: sem estresse (SE), estresse curto (EC), estresse médio (EM) e estresse longo (EL), definidos por quatro períodos 
Tabela 1. Características físicas do solo da área experimental e os parâmetros do ajuste da curva de retenção

\begin{tabular}{lcc}
\hline Característica & Profundidade $-\mathrm{cm}$ \\
\hline Areia grossa $\left(\mathrm{g} \mathrm{kg}^{-1}\right)$ & 310 & 230 \\
Areia fina $\left(\mathrm{g} \mathrm{kg}^{-1}\right)$ & 160 & 120 \\
Silte $\left(\mathrm{g} \mathrm{kg}^{-1}\right)$ & 100 & 60 \\
Argila $\left(\mathrm{g} \mathrm{kg}^{-1}\right)$ & 430 & 580 \\
Classe textural & Argilo-arenosa & Argilosa \\
Densidade aparente $\left(\mathrm{kg} \mathrm{m}^{-3}\right)$ & 1400 & 1320 \\
Capacidade de campo* $\left(\mathrm{g} \mathrm{g}^{-1}\right)$ & 0,2343 & 0,2860 \\
Ponto de murcha**( $\left.\mathrm{g} \mathrm{g}^{-1}\right)$ & 0,1627 & 0,2010 \\
Umidade mínima*** $\left(\mathrm{g} \mathrm{g}^{-1}\right)$ & 0,2057 & 0,2520 \\
$\alpha\left(\mathrm{cm}^{-1}\right)$ & 0,2462 & 0,0071 \\
$\mathrm{M}$ & 0,1563 & 0,3293 \\
$\mathrm{~N}$ & 1,1853 & 1,4910 \\
$\theta_{\mathrm{r}}\left(\mathrm{cm}^{3} \mathrm{~cm}^{-3}\right)$ & 0,0940 & 0,1850 \\
$\theta_{\mathrm{s}}\left(\mathrm{cm}^{3} \mathrm{~cm}^{-3}\right)$ & 0,4100 & 0,3420 \\
$\mathrm{r}^{2}$ & 0,9970 & 0,9950 \\
\hline$*$ Umidade no solo correspondente a tensão de $-0,033 \mathrm{MPa}$ & \\
${ }^{*}$ Umidade no solo correspondente a tensão de $1,5 \mathrm{MPa}$ \\
* $^{*}$ Calculada para um fator de disponibilidade de água no solo igual a 0,4; valor recomendado para \\
os citros, segundo Doorenbos \& Kassam (1979)
\end{tabular}

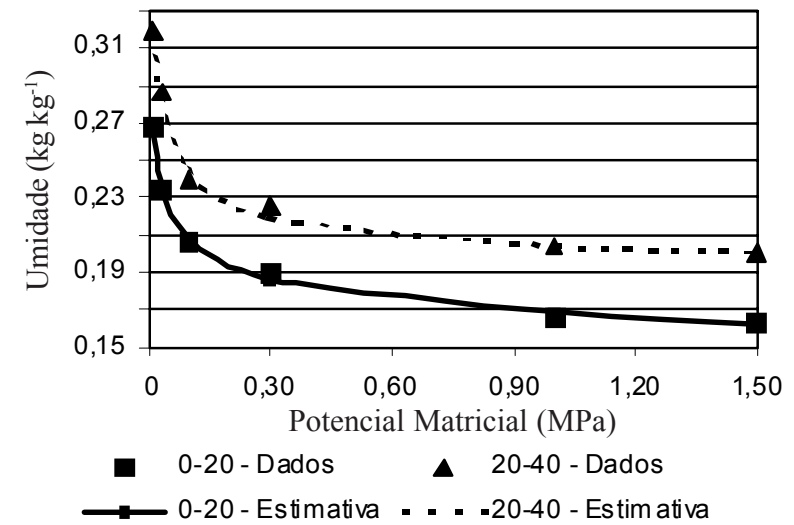

Figura 1. Curvas de retenção de água no solo, da área experimental, nas profundidades de 0 a 20 e de 20 a $40 \mathrm{~cm}$

contínuos sem irrigação, 0, 7, 10 e 13 semanas, respectivamente, durante os meses de junho a agosto de 2000 e nos meses de maio a julho de 2001. Para cada período de estresse hídrico utilizou-se de três porcentagens de área molhada (PW), ou seja, 15, 31 e 46\%, proporcionadas por três microaspersores com bocais e características diferentes.

Desta forma, cada parcela foi caracterizada por uma porcentagem de área molhada e cada subparcela por um período de estresse, tendo assim 12 subparcelas irrigadas por bloco, acrescidas do tratamento testemunha não-irrigado, totalizando $13(12+1)$ tratamentos. Cada parcela foi constituída por oito plantas, as subparcelas por duas e cada bloco por $26(24+2)$ totalizando 78 plantas.

Avaliou-se a produção de lima ácida 'Tahiti' durante os meses de novembro de 2000 a novembro de 2001, cujos dados foram analisados por meio de análise de variância, segundo metodologia apresentada por David \& Kronka (1989). Uma análise foi feita para os 13 tratamentos (incluindo-se a testemunha), em um delineamento em blocos casualizados, e a outra para os 12 tratamentos irrigados, em um delineamento em blocos casualizados em parcelas subdivididas.

Os resultados obtidos nos quatro tratamentos de estresse hídrico foram calculados como a média dos valores obtidos nas três porcentagens de área molhada, e foram comparados pelo teste de Tukey $(p<0,05)$. Para a comparação da testemunha com os quatro tratamentos de estresse utilizou-se o teste de Dunnet $(\mathrm{p}<0,05)$, conforme metodologia apresentada por David \& Kronka (1989).

Na Tabela 2 são apresentados os dados de temperatura, precipitação, e evaporação do Tanque Classe A obtidos no local do experimento, e a estimativa da evapotranspiração potencial da limeira ácida de janeiro de 2000 a novembro de 2001.

Tabela 2. Dados climáticos e de balanço hídrico do local do experimento, de janeiro de 2000 a novembro de 2001

\begin{tabular}{|c|c|c|c|c|c|c|}
\hline \multirow[t]{2}{*}{ Mês/Ano } & $\begin{array}{c}\mathrm{E} \\
\text { diária }\end{array}$ & $\begin{array}{c}\text { ETc } \\
\text { mensal }\end{array}$ & $\begin{array}{c}\mathrm{P} \\
\text { mensal }\end{array}$ & Tmáx & Tmin & Tmed \\
\hline & \multicolumn{3}{|c|}{$\mathrm{mm}$} & \multicolumn{3}{|c|}{${ }^{\circ} \mathrm{C}$} \\
\hline $\mathrm{Jan} / 00$ & & & 287,5 & 34,4 & 20,5 & 27,5 \\
\hline $\mathrm{Fev} / 00$ & & & 195,5 & 34,9 & 20,3 & 27,6 \\
\hline Mar/00 & & & 165,5 & 33,9 & 19,7 & 26,8 \\
\hline $\mathrm{Abr} / 00$ & 3,5 & 43,4 & 72,5 & 33,3 & 16,1 & 24,7 \\
\hline Maio/00 & 2,9 & 36,6 & 12,5 & 31,2 & 13,0 & 22,1 \\
\hline Jun/00 & 2,7 & 32,8 & 7,5 & 31,2 & 9,5 & 20,4 \\
\hline $\mathrm{Jul} / 00$ & 2,8 & 36,4 & 13,8 & 27,6 & 10,0 & 18,8 \\
\hline Ago/00 & 3,8 & 48,9 & 38,8 & 30,5 & 10,9 & 20,7 \\
\hline Set $/ 00$ & 3,7 & 45,9 & 70,6 & 29,0 & 15,8 & 22,4 \\
\hline Out/00 & 6,0 & 76,3 & 60,1 & 34,7 & 17,5 & 26,1 \\
\hline Nov/00 & 4,4 & 54,8 & 202,4 & 30,7 & 19,3 & 25,0 \\
\hline Dez/00 & 5,3 & 68,1 & 220,3 & 33,0 & 20,1 & 26,5 \\
\hline Jan/01 & 5,9 & 75,8 & 184,0 & 34,1 & 20,4 & 27,3 \\
\hline Fev/01 & 7,2 & 82,7 & 143,5 & 36,1 & 20,3 & 28,2 \\
\hline $\mathrm{Mar} / 01$ & 5,2 & 66,4 & 80,3 & 34,6 & 19,0 & 26,8 \\
\hline $\mathrm{Abr} / 01$ & 4,2 & 51,8 & 17,8 & 33,5 & 16,6 & 25,1 \\
\hline Maio/01 & 4,0 & 51,2 & 69,3 & 29,8 & 14,4 & 22,1 \\
\hline Jun/01 & 3,8 & 47,4 & 4,3 & 28,6 & 11,9 & 20,3 \\
\hline $\mathrm{Jul} / 01$ & 3,3 & 42,5 & 0,0 & 30,4 & 9,6 & 20,0 \\
\hline Ago/01 & 4,0 & 51,6 & 0,0 & 30,1 & 9,9 & 20,0 \\
\hline Set/01 & 4,8 & 59,4 & 48,0 & 29,0 & 14,0 & 21,7 \\
\hline Out/01 & 5,0 & 63,9 & 106,0 & 30,7 & 17,2 & 23,9 \\
\hline Nov/01 & 5,6 & 68,8 & 232,9 & 33,2 & 19,9 & 26,5 \\
\hline
\end{tabular}

E - Evaporação do Tanque Classe A; ETc - Evapotranspiração potencial mensal da lima ácida; P - Precipitação mensal; Tmáx - Temperatura máxima média mensal; Tmin - Temperatura mínima média mensal; Tmed - Temperatura média

As datas de início e término dos períodos de estresse hídrico nos anos de 2000 e 2001 podem ser visualizados na Tabela 3. Antes de se iniciar o primeiro período de estresse, todas as plantas foram irrigadas, inclusive a testemunha, e as flores e frutos foram eliminados para garantir condições iniciais idênticas.

O manejo da irrigação foi conduzido através dos dados coletados em um tanque Classe A e em um pluviômetro instalados na estação experimental. Para se determinar a evapotranspiração da cultura de referência (ETo), o coeficiente do tanque $(\mathrm{Kt})$ foi definido em função da umidade relativa do ar, da velocidade do vento e das características de instalação do tanque (circundado com grama), sendo seu valor médio igual a 0,75 (Bernardo, 1995). O coeficiente de cultivo para o cálculo da evapotranspiração da cultura (ETc) foi definido com base nos valores apresentados por Doorenbos \& Pruitt (1977), considerando-se a cobertura vegetal e cultivo isento de ervas daninhas, acrescido em $10 \%$, valor este recomendado para os limões. Desta forma, obteve-se um Kc médio de 0,55. Para o 
Tabela 3. Duração do estresse hídrico

\begin{tabular}{|c|c|c|}
\hline Tratamentos & Início & Término \\
\hline \multicolumn{3}{|l|}{ A. 2000} \\
\hline $\mathrm{SE}$ & Não estressada & \\
\hline $\mathrm{EC}$ & $1^{\circ}$ de junho & 20 de julho \\
\hline EM & $1^{\circ}$ de junho & 10 de agosto \\
\hline EL & $1^{\circ}$ de junho & 31 de agosto \\
\hline \multicolumn{3}{|l|}{ B. 2001} \\
\hline $\mathrm{SE}$ & Não estressada & \\
\hline $\mathrm{EC}$ & $1^{\circ}$ de maio & 19 de junho \\
\hline EM & $1^{\circ}$ de maio & 10 de julho \\
\hline EL & $1^{\circ}$ de maio & 31 de julho \\
\hline
\end{tabular}

SE - sem estresse; EC - estresse curto; EM - estresse médio; EL - estresse longo

manejo da irrigação adotou-se o valor médio de $\mathrm{Kt}(0,75)$ e o coeficiente Kc foi corrigido a medida que a cultura aumentava a porcentagem de cobertura do solo.

Durante a aplicação dos períodos de estresse hídrico a umidade do solo foi determinada semanalmente, de maio a setembro de 2000, e quinzenalmente, de maio a setembro de 2001, utilizando-se o método-padrão de estufa. As amostras de solo foram coletadas a $0,5 \mathrm{~m}$ de distância dos microaspersores, dentro da área da projeção da copa, nas profundidades de 0 a $20 \mathrm{~cm}$ e de 20 a $40 \mathrm{~cm}$. Em função do elevado número de amostras optou-se por monitorar a umidade do solo nos tratamentos não irrigados e de estresse longo.

As datas de floração foram estimadas com o intuito de determinar a época de início de formação dos frutos que originaram cada produção. Para esta estimação considerou-se um somatório de 1493 graus-dia (GD) da abertura da flor até a colheita da lima ácida 'Tahiti', determinados por Souza et al. (2002) como o valor médio para os tratamentos. Empregaramse, para tal, uma temperatura basal de $13{ }^{\circ} \mathrm{C}$ (Reuther, 1973; Koller, 1994) e as temperaturas médias diárias mensais. A partir da data de colheita somaram-se, retroativamente, os graus-dia - GD (diferenças entre a temperatura diária e a temperatura basal, $13{ }^{\circ} \mathrm{C}$ ) até se obter o valor de $1493 \mathrm{GD}$ estimando-se, assim, a data da abertura da flor.

\section{RESULTADOS E DISCUSSÃO}

A interação entre os fatores porcentagem de área molhada e períodos de estresse não foi significativa e apenas verificouse diferença significativa entre os períodos de estresse (Souza et al., 2003), por isso optou-se, neste trabalho, por apresentar e discutir os resultados obtidos nos quatro tratamentos de estresse hídrico, e também os resultados encontrados no tratamento não-irrigado (testemunha).

Na Figura 2 são apresentados os dados de precipitação diária ocorrida durante os meses de janeiro de 2000 a novembro de 2001. Verifica-se, nesta figura, que durante a aplicação do estresse hídrico de junho a agosto 2000 ocorreram 7 dias com chuvas, sendo que as precipitações mais significativas ocorreram em 16 de julho $(13 \mathrm{~mm})$, em 4 de agosto $(8 \mathrm{~mm})$, e no final do período de estresse em 29 de agosto $(30 \mathrm{~mm})$. Já em 2001, durante o período de estresse, de maio a julho, a ocorrência de dias com precipitação foi bem menor, sendo estas insignificantes ( 3 dias com precipitação inferior a $2 \mathrm{~mm}$ ). $\mathrm{O}$ efeito da precipitação ocorrida durante o período de estresse de 2000 pode ser verificado na Figura 3, em que são mostradas as umidades médias do solo para os tratamentos de estresse longo (EL) e para o tratamento não-irrigado (testemunha), nas profundidades de 0 a 20 e de 20 a $40 \mathrm{~cm}$, nos dois períodos de aplicação do estresse hídrico em 2000 e 2001.

Observa-se, na Figura 3, que um pouco antes do término do período de estresse em 2000 ( 22 de agosto) a umidade do solo para as plantas submetidas aos tratamentos de estresse longo

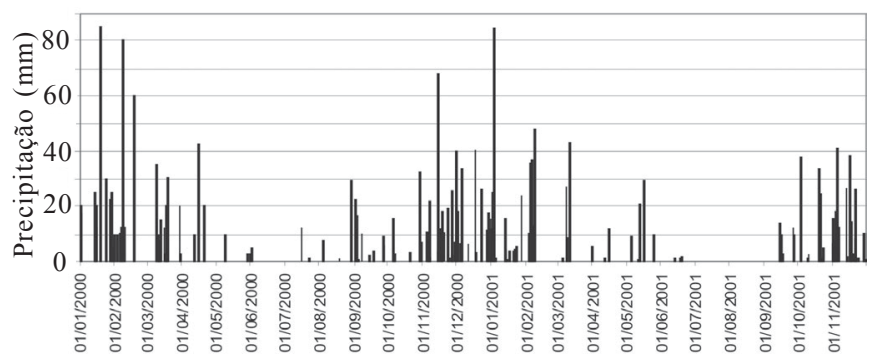

Figura 2. Dados diários de precipitação de janeiro de 2000 a novembro de 2001
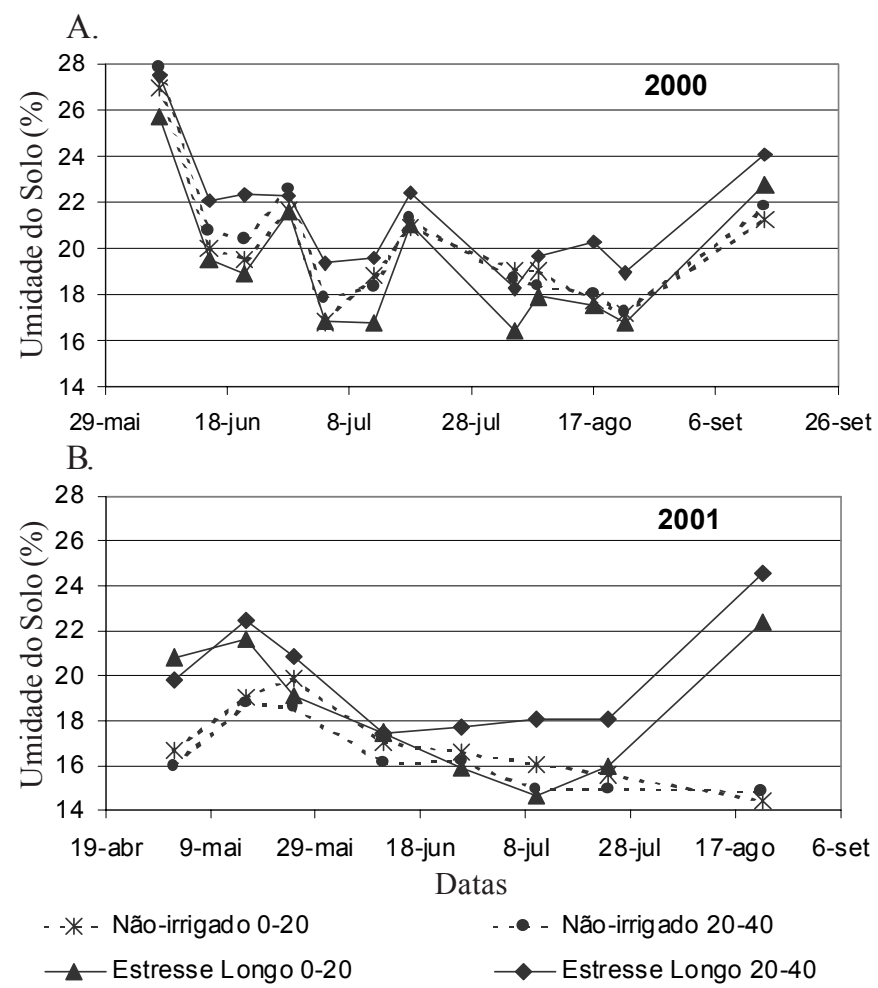

Figura 3. Umidade média do solo, nas plantas do tratamento de estresse longo e do não-irrigado, às profundidades de 0-20 e 20-40 cm, no período em que foi aplicado o estresse hídrico em 2000 e 2001

(EL) e não-irrigado, nas profundidades de 0 a 20 e de 20 a $40 \mathrm{~cm}$, atingiu valores próximos ao ponto de murcha desse solo $(16,27 \%$ na $0-20 \mathrm{~cm}$ e de $20,10 \%$ na $20-40 \mathrm{~cm}$ de profundidade). Este fato mostra que, no final do primeiro período de estresse, as plantas dispunham de pouca umidade no solo na camada de $40 \mathrm{~cm}$. Em conseqüência disso, provavelmente, o sistema radicular se adaptou para extrair água em camadas mais profundas.

Com o início da estação chuvosa em 2 de setembro de 2000 observa-se a elevação do nível de umidade do solo para o tratamento de EL e para a testemunha (tratamento não-irrigado). 
Para o período de estresse aplicado em 2001, também se verifica que a umidade do solo, no final do período de estresse, alcançou valores próximos ao ponto de murcha deste solo.

No ano de 2001, os níveis de água no solo foram inferiores àqueles do ano 2000, em conseqüência do inverno ter sido mais seco, fato este que pode ser verificado na Tabela 2 e também na Figura 2.

Observa-se após o término do período de estresse no ano de 2001 (31 de julho), que o nível de água no solo foi recuperado para as plantas dos tratamentos de EL, enquanto que para as não-irrigadas tal fato não ocorreu.

$\mathrm{Na}$ Tabela 4 são apresentados os valores das datas de colheita para cada mês e as datas de floração estimada. A Tabela 5 contem os valores de produção média, por árvore de lima ácida, para os quatro períodos de estresse, obtidos de novembro de 2000 a novembro de 2001.

Observa-se na Tabela 5 que o tratamento de EM proporcionou a maior produção no mês de novembro 2000, sendo que este valor diferiu dos demais tratamentos de estresse, pelo teste de Tukey $(\mathrm{p}<0,05)$. Observa-se comportamento semelhante para este tratamento, no mês de dezembro desse mesmo ano, sendo que ele não apresentou diferença estatística quando comparado com os tratamentos SE e EC. As plantas submetidas ao EM permaneceram 10 semanas sem irrigação, e a umidade do solo neste período permaneceu abaixo da umidade mínima $(20,6 \%$ na $0-20 \mathrm{~cm}$ e $25,2 \%$ na $20-40 \mathrm{~cm}$ de profundidade) durante quase todo o período de aplicação do estresse, como pode ser observado na Figura 3. A produção obtida nos meses de novembro e dezembro de 2000 foi proveniente de flores que se abriram entre o final de junho e final de julho, respectivamente (Tabela 4), ou seja, durante a aplicação do estresse.

Em novembro de 2000, o tratamento SE proporcionou a menor produção, não diferindo dos tratamentos de EC e EL $(\mathrm{p}<0,05)$, em virtude, possivelmente, de uma menor indução floral, que resultou em um menor número de flores e conseqüentemente em uma menor produção, o que vem reforçar a colocação de Doorenbos \& Kassam (1979) de que, para atingir maior produção, a lima ácida necessita de um período de repouso de dois meses de duração, induzido por baixas temperaturas ou por estresse hídrico. Salienta-se que a duração do período de estresse depende das condições edafoclimáticas.
Em dezembro de 2000 as árvores sujeitas ao tratamento EL apresentaram a menor produção; para a colheita desse mês, a data estimada de floração foi 31 de julho, significando que os frutos oriundos dessa floração não vingaram para as árvores sujeitas ao tratamento EL pois, nessa época, a irrigação não havia sido retomada para este tratamento, que só voltou a ser irrigado em início de setembro de 2000. Em janeiro de 2001, apesar da diferença não ter sido significativa, as plantas do tratamento EL apresentaram o maior valor absoluto para a produção, em razão de essa produção ser proveniente de flores que se abriram em 20 de setembro. Nesta data, a irrigação para as plantas do tratamento EL já havia sido retomada, o que ocasionou maior vingamento dos frutos. Outro fator que possivelmente influenciou, é que havia maior reserva acumulada disponível para essas plantas.

Essas diferenças significativas de produção em novembro e dezembro de 2000, mostram que o estresse hídrico imposto às árvores nos tratamentos EC, EM e EL, durante os meses de junho a agosto de 2000 refletiu significativamente na produção da lima ácida, nos meses subseqüentes ao estresse.

Salienta-se que, além do estresse hídrico, as plantas ficaram sujeitas ao estresse térmico, inevitável nessa região na época de inverno. Observa-se na Tabela 2 que as temperaturas mínimas médias para os meses de junho, julho e agosto de 2000 , foram $9,5,10$ e $10,9^{\circ} \mathrm{C}$, respectivamente, e em 2001 foram de $11,9,9,6$ e $9,9{ }^{\circ} \mathrm{C}$. Conseqüentemente, essas baixas temperaturas influenciaram a produção em novembro e dezembro de 2000 e, em parte, a produção de janeiro de 2001. Este fato reforça o resultado obtido por Southwick \& Davenport (1986) que observaram uma maior floração em plantas submetidas à temperatura noturna de $10^{\circ} \mathrm{C}$.

Durante os meses de janeiro a maio de 2001, período da safra, não ocorreram diferenças significativas entre os tratamentos de estresse, aplicados entre junho e agosto de 2000, o que é devido ao fato de que, neste período, os tratamentos de estresse não tiveram influência direta, uma vez que a partir de janeiro a produção foi proveniente de flores que se abriram a partir de setembro, e neste mês a irrigação já havia sido reiniciada, para todos os tratamentos irrigados. Outro fator que se supõe ter influenciado a produção de janeiro a maio, foi a precipitação verificada a partir de novembro de 2000. Segundo

Tabela 4. Datas das colheitas e das florações

\begin{tabular}{|c|c|c|c|c|c|c|c|c|c|c|c|c|c|}
\hline & \multicolumn{2}{|c|}{2000} & \multicolumn{11}{|c|}{2001} \\
\hline & Nov & Dez & Jan & Fev & Mar & Abr & Mai & Jun & Jul & Ago & Set & Out & Nov \\
\hline Colheita & $30 / 11$ & $15 / 12$ & $15 / 01$ & $15 / 02$ & $19 / 03$ & $18 / 04$ & $17 / 05$ & $20 / 06$ & $24 / 07$ & $30 / 08$ & $25 / 09$ & $30 / 10$ & $30 / 11$ \\
\hline Floração & $28 / 06$ & $31 / 07$ & $20 / 09$ & $29 / 09$ & $04 / 12$ & $01 / 01$ & $22 / 01$ & $10 / 02$ & $25 / 02$ & $16 / 03$ & $02 / 04$ & $03 / 05$ & $23 / 06$ \\
\hline
\end{tabular}

Tabela 5. Produção média por árvore, em kg, de lima ácida 'Tahiti', para os quatro períodos de estresse hídrico

\begin{tabular}{|c|c|c|c|c|c|c|c|c|c|c|c|c|c|c|}
\hline & \multicolumn{2}{|c|}{2000} & \multicolumn{12}{|c|}{2001} \\
\hline & Nov & Dez & Jan & Fev & Mar & $\mathrm{Abr}$ & Mai & Jun & Jul & Ago & Set & Out & Nov & Total \\
\hline SE & $1,7 \mathrm{~b}$ & $4,0 \mathrm{ab}$ & $11,2 \mathrm{a}$ & $7,8 \mathrm{a}$ & $7,5 \mathrm{a}$ & $9,8 \mathrm{a}$ & $4,6 \mathrm{a}$ & $13,8 \mathrm{a}$ & $8,2 \mathrm{a}$ & $9,4 \mathrm{a}$ & $2,2 \mathrm{bc}$ & $0,7 \mathrm{~b}$ & $10,2 \mathrm{a}$ & $91,2 \mathrm{a}$ \\
\hline $\mathrm{EC}$ & $3,4 \mathrm{~b}$ & $4,3 \mathrm{ab}$ & $8,2 \mathrm{a}$ & $4,4 \mathrm{a}$ & $6,9 a$ & $9,7 \mathrm{a}$ & $3,9 \mathrm{a}$ & $11,7 \mathrm{a}$ & $8,4 \mathrm{a}$ & $8,8 \mathrm{a}$ & $4,8 \mathrm{a}$ & $2,7 \mathrm{a}$ & $12,9 \mathrm{a}$ & $90,2 \mathrm{a}$ \\
\hline EM & $6,5 \mathrm{a}$ & $6,5 \mathrm{a}$ & $10,7 \mathrm{a}$ & $4,0 \mathrm{a}$ & $6,5 \mathrm{a}$ & $8,8 \mathrm{a}$ & $4,0 \mathrm{a}$ & $8,8 \mathrm{~b}$ & $4,7 \mathrm{~b}$ & $7,3 \mathrm{ab}$ & $3,7 \mathrm{ab}$ & $3,0 \mathrm{a}$ & $8,4 \mathrm{ab}$ & 82,9 a \\
\hline EL & $1,9 \mathrm{~b}$ & $3,4 \mathrm{~b}$ & $13,1 \mathrm{a}$ & $5,0 \mathrm{a}$ & $6,7 \mathrm{a}$ & $9,7 \mathrm{a}$ & $4,6 \mathrm{a}$ & $8,8 \mathrm{~b}$ & $3,0 \mathrm{~b}$ & $4,7 \mathrm{~b}$ & $3,1 \mathrm{~b}$ & $1,7 \mathrm{ab}$ & $3,8 \mathrm{~b}$ & $69,6 \mathrm{a}$ \\
\hline Média & 3,2 & 4,4 & 10,7 & 5,4 & 6,9 & 9,4 & 4,2 & 10,5 & 5,8 & 7,6 & 3,4 & 2,1 & 8,8 & 83,6 \\
\hline
\end{tabular}

SE - sem estresse; EC - estresse curto; EM - estresse médio; EL - estresse longo

As médias seguidas de pelo menos uma mesma letra, na mesma coluna, não diferem ao nível de $5 \%$, pelo teste de Tukey 
Paulino \& Volpe (2001), a precipitação ocorrida em dezembro tem grande correlação com a produção de laranja 'Pêra', uma vez que a precipitação é responsável pela fixação dos frutos.

As precipitações dos meses de novembro de 2000 a março de 2001 (Figura 2) favoreceram o vingamento dos frutos nesse período, mascarando o efeito da irrigação. A precipitação iniciada em novembro, teve influência direta sobre a formação dos frutos colhidos a partir de março de 2001. Este fato pode ser melhor compreendido observando-se a Tabela 4 , em que os frutos colhidos em março e abril de 2001 foram provenientes de flores abertas em início de dezembro e início de janeiro, respectivamente.

Durante o segundo período de estresse hídrico, imposto às árvores a partir de maio de 2001, a umidade mínima, na camada de 0 a $20 \mathrm{~cm}$, ocorreu a partir de final de maio, e na camada de 20 a $40 \mathrm{~cm}$ desde o início do período de estresse (Figura 3).

$\mathrm{Na}$ Tabela 5, observam-se diferenças significativas na produção de lima ácida nos meses de junho a setembro de 2001 em conseqüência, do segundo período de estresse hídrico. Com a interrupção da irrigação a partir de maio, observa-se que a produção das plantas dos tratamentos EM e EL, durante o mês de junho, foi inferior à dos tratamentos SE e EC. No mês de agosto de 2001 os tratamentos SE, EC e EM proporcionaram maiores produções. O tratamento EM não diferiu dos tratamentos SE e EC em consequência do retorno da irrigação que, neste tratamento, ocorreu em 10 de julho de 2001.

Provavelmente a produção tenha sido alta nos meses de junho a agosto de 2001, em sobretudo, para os tratamentos SE e EC, em razão de ser proveniente de flores que se abriram a partir de início de fevereiro (data de floração estimada para a colheita de junho) a início de abril (para a colheita de setembro), como se pode observar na Tabela 4. De janeiro a março, meses de elevada evapotranspiração e de ocorrência de grandes períodos sem chuva, como pode ser observado na Figura 2, foi verificado problemas na condução da irrigação devido a vários entupimentos dos filtros, ocasionados pela elevada turbidez da água captada para a irrigação, levando a uma redução na pressão e na vazão dos microaspersores, o que resultou em uma lâmina menor de irrigação aplicada, ocasionando assim um período de estresse hídrico nesses meses, que possivelmente influenciou a floração de fevereiro e março de 2001.

Observa-se, na Tabela 5, que os tratamentos EL e EM apresentaram as menores produções em junho, julho e agosto de 2001, indicando que, durante um período de estresse hídrico, a limeira ácida reduz a produção, fato que pode ser explicado pela diminuição do ritmo de crescimento do fruto, pela queda de flores e de frutos, e pela menor absorção de nutrientes, dentre outros, o que reforça a importância da irrigação para o aumento de produtividade de um pomar (Vieira, 1988b) assegurando maior vingamento de flores e frutos (Vieira, 1991, citado por Pires, 1992). As plantas submetidas ao tratamento EL ainda apresentaram uma das menores produções no mês de novembro de 2001, porque as flores que vingaram no final deste tratamento não contribuíram de forma significativa para aumentar a produção das árvores, uma vez que, em novembro de 2001, os frutos colhidos foram provenientes de flores que se abriram em final de junho, época em que a irrigação não havia sido retomada para este tratamento, voltando a ser irrigado somente em 31 de julho.
No mês de setembro de 2001, o tratamento de estresse curto (EC) proporcionou a maior produção, diferindo dos tratamentos SE e EL. Em outubro de 2001, a maior produção foi obtida nas plantas submetidas aos tratamentos EM e EC, enquanto, em novembro de 2001, o tratamento que proporcionou a maior produção foi EC seguido por SE e EM. O tratamento SE, provavelmente, não diferiu dos tratamentos EM e EC, em novembro de 2001, em razão do estresse térmico sofrido nos meses de junho a agosto de 2001, que favoreceu a produção do mês de novembro. $\mathrm{O}$ fato de as plantas dos tratamentos EM e EC terem apresentado maiores produções em setembro, outubro e novembro de 2001 está relacionado ao estresse hídrico, imposto às árvores a partir de maio de 2001, bem como ao estresse térmico. A data estimada de floração, para os frutos colhidos no mês de setembro, foi 2 de abril de 2001 e para o mês de outubro foi 3 de maio, e para os frutos colhidos em novembro foi 23 de junho. Em 23 de junho, a irrigação já havia sido retomada para as plantas do tratamento EC, enquanto em 10 de julho, as plantas do tratamento EM voltaram a ser irrigadas, favorecendo, desta forma o vingamento dos frutos destes dois tratamentos.

Provavelmente, o tratamento sem estresse (SE) tenha resultado em menores produções em setembro e outubro de 2001, em virtude de a colheita nesses meses ser proveniente de flores que abriram em início de abril e início de maio de 2001, respectivamente. Nessa época, este tratamento não se encontrava em situação de estresse hídrico ou térmico, o que, provavelmente, ocasionou um menor número de flores, em abril e maio, e menor colheita em setembro e outubro. Outro fato que também pode ter ocasionado uma redução na produção é o baixo nível das reservas das plantas ocasionado pelas elevadas produções anteriores.

Portanto, o segundo período de estresse hídrico, imposto aos tratamentos EC, EM e EL afetou a produção de lima ácida 'Tahiti', durante os meses de estresse e nos meses subsequentes ao estresse.

A duração do estresse hídrico influenciou a época e a produtividade sazonal do limoeiro, porém não influenciou, significativamente, a produção total.

Na Figura 4 são apresentados os gráficos de distribuição temporal da produção de lima ácida para os tratamentos SE, EC, EM, EL e para a testemunha (tratamento não-irrigado). Observa-se, nesta figura, que a produção temporal das plantas submetidas ao EL é a que apresenta comportamento temporal mais similar ao tratamento não-irrigado, não tendo este tratamento diferido significativamente da testemunha, ao nível de 5\% pelo teste de Dunnett, em nenhum dos meses avaliados. Isto provavelmente ocorreu em razão de o tratamento EL ter permanecido 13 semanas sem irrigação, durante os meses de junho a agosto de 2000, e 13 semanas sem irrigação de maio a julho de 2001, ou seja, dois períodos que coincidem com a época seca desses anos (Tabela 2). Nos outros meses em que o tratamento EL foi irrigado, de setembro de 2000 a abril de 2001 e de agosto a novembro de 2001, embora as plantas do tratamento testemunha não tenham sido irrigadas, elas dispunham de água proveniente das precipitações, que neste período foram bem significativas, como se pode observar na Tabela 2. 
A.

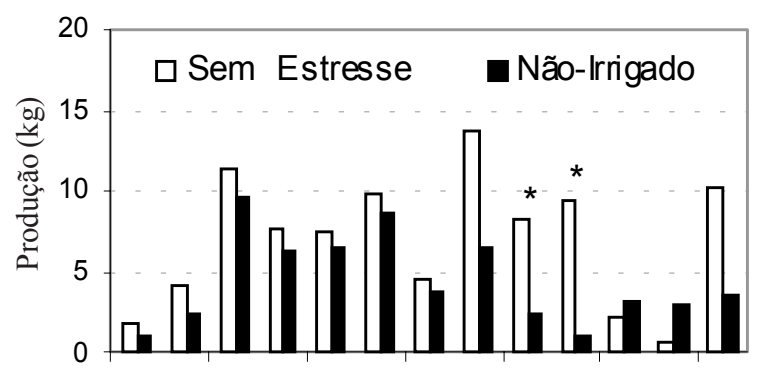

B.

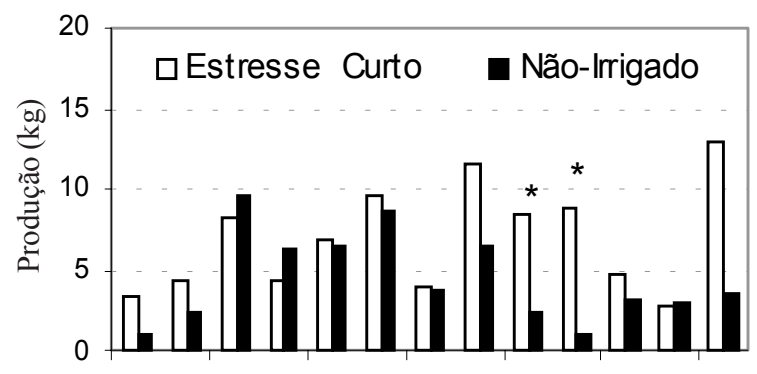

C.

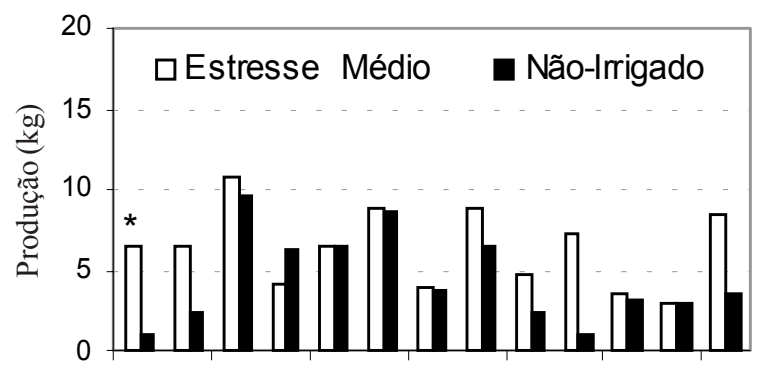

D.

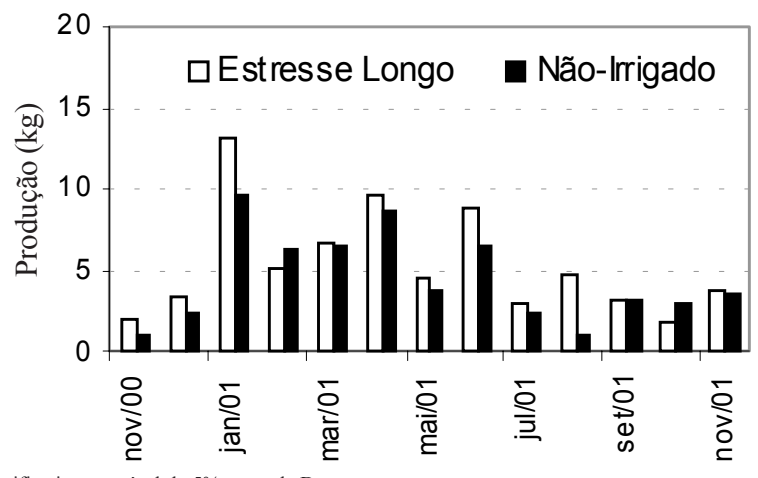

* Significativo em nível de $5 \%$, teste de Dunnett

Figura 4. Produção de lima ácida 'Tahiti', em Kg, para os quatro tratamentos de estresse hídrico e para o tratamento nãoirrigado, de novembro de 2000 a novembro de 2001

$\mathrm{Na}$ Figura 4, observa-se ainda, que as diferenças significativas ocorreram somente para o mês de novembro de 2000, no tratamento de EM, e para os meses de julho e agosto de 2001 para os tratamentos SE e EC.

\section{CONCLUSÕES}

1. A aplicação do estresse hídrico aumentou a produção nos meses subseqüentes ao estresse.

2. A aplicação do estresse hídrico de duração média e longa, 10 e 13 semanas sem irrigação, respectivamente, durante os meses de maio a julho de 2001, reduziu a produção de lima ácida durante os meses de sua aplicação.

3. A duração do estresse hídrico influenciou a época e a produtividade sazonal da limeira ácida 'Tahiti', porém não influenciou significativamente a produção total.

4. Para a região de Visconde do Rio Branco, MG, um período de déficit hídrico aplicado durante a estação seca, de maio a setembro, com uma duração de 7 a 10 semanas é necessário para que se obtenha uma maior produção de lima ácida 'Tahiti' na entressafra.

\section{AGRADECIMENTOS}

O primeiro autor agradece ao $\mathrm{CNPq}$, pelo apoio financeiro. Aos departamentos de Engenharia Agrícola e de Fitotecnia, pelo apoio técnico. Aos funcionários da garagem central da UFV e da Estação Experimental da Sementeira, pelo apoio durante a execução prática do presente trabalho. Aos estagiários e a todos aqueles que colaboraram para a realização deste trabalho.

\section{LITERATURA CITADA}

AGRIANUAL 99 - Anuário Estatístico da Agricultura Brasileira. São Paulo: FNP / M\&S, 1999. p.250-286.

Bernardo, S. Manual de Irrigação. Viçosa, MG: UFV, Imprensa Universitária, 1995. 657p.

Caetano, A.A.; Figueiredo, J.O.; Franco, J.F. Uso de ethephon e óleo mineral para alterar a época de produção do limão 'Tahiti'. In: Congresso Brasileiro de Fruticultura, 6, 1981, Recife. Anais... Recife: Sociedade Brasileira de Fruticultura, 1981. v.2, p.723-731.

Coelho, Y.S. Lima ácida 'Tahiti' para exportação: aspectos técnicos da produção. Brasília: EMBRAPA - SPI, 1993.35p. Série Publicações Técnicas FRUPEX, 1

David, A.B.; Kronka, S.N. Experimentação Agrícola. Jaboticabal: FUNEP, 1989. 247p.

Doorenbos, J.; Kassam, A.H. Yield response to water. Rome: FAO, 1979. 306p. Irrigation and Drainage, 33

Doorenbos, J.; Pruitt, W.O. Crop water requirement. Rome: FAO, 1977. 144p. Irrigation and Drainage, 24.

Hall, A.E.; Khairi, M.M.A.; Asbell, C.W. Air and soil temperature effects on flowering of citrus. Journal American Socity Horticultural Science, St. Joseph, Michigan, USA, v.3, n.102, p.261-263, 1977 .

Koller, O.C. Citricultura: laranja, limão, tangerina. Porto Alegre, RS: Editora Rígel Ltda. 1994. 446p.

Lima, J.E.O. Florescimento e frutificação em citros. Laranja, Cordeirópolis, v.2, n.10, p.523-530, 1989.

Marcondes, P.T.S.; Coelho, Y.S. Manejo da florada da Lima ácida 'Tahiti' com reguladores de crescimento e desbaste manual. In: Congresso Brasileiro de Fruticultura, 14, Reunião Internacional de Horticultura Tropical, Simpósio Internacional de Mirtáceas, 42, 1996, Curitiba, PB. Anais...Curitiba: Sociedade Brasileira de Fruticultura, 1996. v.1, p.139. 
Paulino, S.E. P.; Volpe, C.A. Relação entre produção de laranjeira 'Pêra' e algumas variáveis meteorológicas. In: Congresso Brasileiro de Agrometerologia, 12 e Reunião Latino Americana de Agrometeorologia, 3, 2001, Fortaleza. Anais... Fortaleza: 2001.p. 689-690.

PESAGRO, RIO - Empresa de Pesquisa Agropecuária do Estado do Rio de Janeiro. Ganho expressivo com limão fora de época. (http://www.pesagro.com/pes4.htm\#aplicada). 24/05/1999.

Pires, R.C.M. Manejo da água na irrigação dos citros. Laranja, Cordeirópolis, v.13, n.1, p.237-260, 1992.

Reuther, W. Climate and citrus behavior. In: Reuther, W. The Citrus industry, Riverside: University of California, v.3, 1973. p.280-337. cap. 9

Sanchez B, M.J.; Torrecillas, A.; Del Amor, F.; Leon, A.; Sanchez Toribio, M.I. Efectos del riego en aspectos de la biologia floral del Limonero Verna. Fruticultura Profesional, Barcelona, Espanha, n.22, p.30-33, 1989.

Southwick, S.M.; Davenport, T.L. Characterization of water stress and low temperature effects on flower induction in citrus. Plant Physiology, Maryland, USA, v.81, p.26-29, 1986.

Southwick, S.M.; Davenport, T.L. Modification of the water stress-induced floral response in 'Tahiti' Lime. Journal American Society Horticultural Science, St. Joseph, Michigan, USA, v.2, n.112, p.231-236, 1987.
Souza, M.J.H.; Ramos, M.M.; Siqueira, D.L.; Mantovani, L.C.; Costa, L.C.; Lhamas, A.J.M.; Cecon, P.R.; Salomão L.C.C. Graus-dia para o período antese-colheita da lima ácida 'Tahiti' irrigada e não irrigada. In: IX Reunião Argentina de Agrometeorologia, 9, 2002, Vaqueria, Córdoba, Argentina. Anais... Vaqueria, Córdoba: Sociedade Argentina de Agrometeorologia. 2002. CD-Rom

Souza, M.J.H.; Ramos, M.M.; Siqueira, D.L.; Mantovani, E.C.; Costa, L.C.; Lhamas, A.J.M.; Cecon, P.R.; Salomão L.C.C. Produção e qualidade dos frutos da limeira submetida a diferentes porcentagens de área molhada. Revista de Engenharia Agrícola e Ambiental. Campina Grande - PB, v.7, n.2, p.245-250, 2003.

van Genuchten, M.T. A Closed-form equation for predicting the hydraulic conductivity of unsaturated soils. Soil Science Society American Journal, Madison, n.44, p. 892-898, 1980.

van Lier, Q. de J.; Dourado Neto, D. Valores extremos de umidade do solo referentes ao modelo de van Genuchten. Revista Brasileira de Ciência do Solo, Campinas, v.17, p.325329, 1993.

Vieira, D.B. Fertirrigação e manejo de irrigação em citros. Laranja, Cordeirópolis, v.2, n.9, p.369-376, 1988a.

Vieira, D.B. Produtividade e irrigação. In: Simpósio de Citricultura. Produtividade dos Citros, 3, 1988, Jaboticabal, SP. Anais... Jaboticabal: FUNEP, 1988b. p.185-193. 